\title{
Characteristics and antioxidative ability of defatted rice bran extracts obtained using several extractants under subcritical conditions
}

\author{
Tai-Ying Chiou, Akane Ogino, Takashi Kobayashi, and Shuji Adachi* \\ Division of Food Science and Biotechnology, Graduate School of Agriculture, Kyoto University, Sakyo-ku, Kyoto 606-8502, Japan
}

\begin{abstract}
Defatted rice bran was treated with water, $50 \%(v / v)$ ethanol, ethanol, $50 \%(v / v)$ acetone, or acetone. The treatment temperature and time were fixed at $230^{\circ} \mathrm{C}$ and $5 \mathrm{~min}$, respectively. The treatment with $50 \%(v / v)$ acetone produced the highest yield of 0.549 g-extract/g-bran, and the extract exhibited the highest DPPH radical scavenging activity of $0.495 \mathrm{mmol}$-ascorbic acid/g-extract. The extract obtained with $50 \%$ (v/v) acetone showed the higher UV absorbance and highest amount of hydrophobic substances in the HPLC analysis than the other extracts, and it also showed the highest antioxidative ability in both the rancidity test at $105^{\circ} \mathrm{C}$ and bulk oil system at $60^{\circ} \mathrm{C}$ for the longest induction period of $4.9 \mathrm{~h}$ and $14.4 \mathrm{~h}$, respectively. However, the extracts obtained using various extractants showed no effect on the oxidation rate constant of linoleic acid in the bulk oil system.
\end{abstract}

Key words: defatted rice bran, subcritical fluid, antioxidative ability, rancidity test, bulk oil system

\section{INTRODUCTION}

Rice bran is a part of the rice kernel (Oryza sativa) containing pericarp, aleurone, and subaleurone, and is a byproduct of the rice-milling process ${ }^{1}$. There are 63 to 76 million tons of rice bran produced each year in the world. Rice bran is known to contain various useful substances. For example, rice bran protein is rich in lysine and has a hypoallergenic property that makes it suitable for infant food formulations ${ }^{2)}$. In addition, the water-soluble fraction of rice bran could lower serum glucose levels, and rice bran fiber concentrates were effective in lowering serum total cholesterol, LDL-cholesterol, and apolipoprotein B levels in diabetic (Types I and II) human subjects ${ }^{3)}$. In a whole grain, rice bran contains $70-90 \%$ of the total phenolic compounds which are known to possess an antioxidative ability and UV-B tolerance ${ }^{4-6)}$. Moreover, the phenolic compounds, such as ferulic acid and its derivatives, are reported to have beneficial effects against cancer, cardiovascular disease, diabetes, and Alzheimer's disease ${ }^{7)}$. However, defatted rice bran is usually disposed as an agro-waste after the oil production process although various useful substances still remain.

In order to obtain the useful substances from defatted rice bran, various methods have been investigated. For example, an ultrasonic extraction with the pretreatment by supercritical carbon dioxide and 5\% sulfuric acid was used to recover vitamins B and phytic acid from the rice bran, respectively ${ }^{8,9)}$. Enzymes, such as cellulase, an ultrasonic assisted acid/alkaline solution, and subcritical water were also employed to facilitate extraction of the oligosaccharides, dietary fiber, and protein from the defatted rice $\operatorname{bran}^{10-15)}$.

Subcritical organic solvents such as compressed hot water/ethanol and water/acetone were used for the extraction of biomass from woods ${ }^{16,17)}$. The former was useful in extraction of nonylphenol polyethoxy carboxylates from industrial and municipal sludge ${ }^{18)}$, and the latter was also used for organosolv pulping of wheat straw to obtain paper sheets $^{19)}$. However, except for our previous studies ${ }^{20,21)}$, there are few studies concerning the extraction of defatted rice bran by subcritical organic solvents. In this study, we used several organic solvents as extractants at the treatment temperature and time of $230^{\circ} \mathrm{C}^{21)}$ and $5 \mathrm{~min}^{22)}$, respectively. The extracts were characterized for total carbohydrate, protein, and total phenolic contents, and the 1,1-diphenyl-2-picrylhydrazyl (DPPH) radical scavenging activity. The antioxidative ability of the extracts was also evaluated by the rancidity test and autoxidation in the bulk oil system. The former was based on the principle of the Rancimat method ${ }^{23)}$ with the reaction at $105^{\circ} \mathrm{C}$, and the

*Correspondence to: Shuji Adachi, Division of Food Science and Biotechnology, Graduate School of Agriculture, Kyoto University, Sakyo-ku, Kyoto 606-8502, Japan

E-mail: adachi@kais.kyoto-u.ac.jp

Accepted July 31, 2012 (recieved for review June 3, 2012)

Journal of Oleo Science ISSN 1345-8957 print / ISSN 1347-3352 online

http://www.jstage.jst.go.jp/browse/jos/ http://mc.manusriptcentral.com/jjocs 


\section{T.-Y. Chiou, A. Ogino, T. Kobayashi et al.}

latter was an autoxidation process ${ }^{24)}$ of linoleic acid at $60^{\circ} \mathrm{C}$ measured by gas chromatography.

\section{MATERIALS AND METHODS}

\subsection{Materials}

The defatted rice bran was supplied by Tsuno Food Industrial (Wakayama, Japan) after the deoiling process by the official AOCS Ba 3-38 method $^{25)}$. Crystallized bovine serum albumin (BSA, 99\% purity), methyl palmitate, and DPPH were purchased from Wako Pure Chemical Industries (Osaka, Japan). Sodium hydroxide, sodium carbonate, and L-ascorbic acid (VC, purity > 99.5\%) were purchased from Nacalai Tesque (Kyoto, Japan). Gallic acid, linoleic acid (purity $>99.5 \%$ ), and Folin-Ciocalteu's phenol reagent were purchased from Sigma-Aldrich Japan(Tokyo, Japan), Tokyo Chemical Industry (Tokyo, Japan), and ICN Biomedicals (Aurora, OH, USA), respectively. Distilled water was used throughout the study.

\subsection{Extraction from defatted rice bran under subcritical conditions}

Water, $50 \%(\mathrm{v} / \mathrm{v})$ aqueous ethanol, ethanol, $50 \%(\mathrm{v} / \mathrm{v})$ aqueous acetone, and acetone were used as the extractants. Defatted rice bran $(1.5 \mathrm{~g})$ and an extractant $(75 \mathrm{~mL})$ were placed in a TVS-N2 type SUS-316 stainless steel vessel(Taiatsu Techno, Osaka, Japan) with a working volume of $117 \mathrm{~mL}$ (30 mm i.d. $\times 165.5 \mathrm{~mm}$ height), and the vessel was tightly sealed. The temperature of the mixture was increased to $230^{\circ} \mathrm{C}$ by heating the vessel using a mantle heater (TXN-700B, As One, Osaka, Japan). The heating time for the vessel to reach $230^{\circ} \mathrm{C}$ was ranged from $32-38 \mathrm{~min}^{21)}$. After $5 \mathrm{~min}$ at $230^{\circ} \mathrm{C}$ for the extraction, the vessel was subsequently immersed in an ice-water bath and cooled to room temperature. The crude extract solution was then filtered through filter paper(No. 2, Toyo Roshi Kaisha, Tokyo, Japan) to obtain the clear solution. The filtered extract solution $(30 \mathrm{~mL})$ was used for the determination of the yield, and the rest was subjected to a rotary evaporator (N-1100 AN, Tokyo Rikakikai, Tokyo, Japan) to remove the solvent. The dried extract was re-dissolved in $50 \%(\mathrm{v} / \mathrm{v})$ aqueous ethanol and stored at $4{ }^{\circ} \mathrm{C}$ until used.

\subsection{Properties of defatted rice bran extracts}

\subsubsection{Yield}

As already described, $30 \mathrm{~mL}$ of the filtered extract were used for determining the yield. After removing the solvent by a rotary evaporator, the extract was further dried in an oven (DNF-400, Yamato Scientific, Tokyo, Japan) at $105^{\circ} \mathrm{C}$ for $3 \mathrm{~h}$ and then weighed.

\subsubsection{Total carbohydrate content}

The total carbohydrate content was determined by the modified phenol-sulfuric acid method according to Dubois et $a l .{ }^{26)}$. Concentrated sulfuric acid (2.5 mL) and an $80 \%$ (w/ w) aqueous phenol solution $(25 \mu \mathrm{L})$ were mixed with a properly water-diluted sample $(1 \mathrm{~mL})$. After standing at room temperature for $10 \mathrm{~min}$, the sample was placed in a water bath $\left(30^{\circ} \mathrm{C}\right)$ for $30 \mathrm{~min}$. The absorbance at $490 \mathrm{~nm}$ was measured using a UV-1200 spectrophotometer (Shimadzu, Kyoto, Japan), and the total carbohydrate content was determined using glucose as the standard.

\subsubsection{Protein content}

The protein content was determined according to the Lowry-Folin method ${ }^{27)}$ with some modifications. An alkaline solution, containing $0.1 \mathrm{~mol} / \mathrm{L}$ sodium hydroxide and $2 \%$ $(\mathrm{w} / \mathrm{v})$ sodium carbonate, and a copper reagent, containing $0.5 \%(\mathrm{w} / \mathrm{v})$ copper (II) pentahydrate and 1\% (w/v) trisodium citrate, were separately prepared. Just before use, the alkaline copper reagent was prepared by mixing $100 \mathrm{~mL}$ of an alkaline solution with $2 \mathrm{~mL}$ of copper reagent. The alkaline copper reagent $(2 \mathrm{~mL})$ was subsequently mixed with $0.4 \mathrm{~mL}$ of a properly water-diluted sample, and the mixture was stored at room temperature for $15 \mathrm{~min}$. The mixture was then mixed with two-fold water-diluted Folin-Ciocalteu's phenol reagent $(0.2 \mathrm{~mL})$, and then stored at room temperature for $30 \mathrm{~min}$. The absorbance at $750 \mathrm{~nm}$ was measured by a Shimadzu UV-1200. BSA was used as the standard for making a calibration curve.

\subsubsection{Total phenolic content}

The total phenolic content was determined using FolinCiocalteu's phenol reagent according to a previously reported method ${ }^{28,29)}$. Ten-fold water-diluted Folin-Ciocalteu's phenol reagent $(100 \mu \mathrm{L})$ was mixed with a properly water-diluted sample $(400 \mu \mathrm{L})$, and the mixture was stored at room temperature for $15 \mathrm{~min}$. One milliliter of a $7.5 \%$ $(\mathrm{w} / \mathrm{v})$ sodium carbonate aqueous solution was subsequently mixed with the mixture, which was then stored for another $15 \mathrm{~min}$. The mixture was next mixed with water $(3.5 \mathrm{~mL})$, and stored in dark for $2 \mathrm{~h}$. The absorbance at $765 \mathrm{~nm}$ was measured by a Shimadzu UV-1200. A calibration curve was constructed using gallic acid as the standard.

2.3.5 DPPH radical scavenging activity

The DPPH radical scavenging activity of the defatted rice bran extracts was determined according to the method developed by Fujinami et al. ${ }^{30)}$ with some modifications. The DPPH solution was prepared by dissolving DPPH in ethanol at a concentration of $0.5 \mathrm{mmol} / \mathrm{L}$. An extract was properly diluted with the $50 \%(\mathrm{v} / \mathrm{v})$ aqueous ethanol, and $0.8 \mathrm{~mL}$ of it was mixed with $0.2 \mathrm{~mL}$ of the DPPH solution in an Eppendorf light-blocking tube. After the mixture was stored at room temperature for $30 \mathrm{~min}$, the absorbance at $515 \mathrm{~nm}$ was measured. The radical scavenging activity, $R S$, as a percent, was estimated by the following equation:

$$
R S=\frac{A-B+C}{A} \times 100 \%
$$

where $A$ and $B$ are the absorbances of the DPPH solutions 
mixed with the $50 \%(\mathrm{v} / \mathrm{v})$ aqueous ethanol (control) and extract solution, respectively. $C$ is a blank of the extract solution without the DPPH solution. The L-ascorbic acid was used as a standard at 18-36 $\mu \mathrm{mol} / \mathrm{L}$ for making a calibration curve. The DPPH radical scavenging activity of the extracts was defined as the amount needed to reduce the initial DPPH concentration by $50 \%$, and represented as mmol-VC/g-bran or mmol-VC/g-extract.

2.3.6 Absorption spectra and HPLC analyses

The absorption spectra of the extract solutions were measured using a UV-1600 spectrophotometer (Shimadzu, Kyoto, Japan) in the wavelength range of 200 to $400 \mathrm{~nm}$.

Since the extracts contain substances with various polarities, the HPLC analysis was carried out in the gradient elution mode. The HPLC system consisted of two pumps (LC-10AD VP, Shimadzu, Kyoto, Japan), a YMC-Pack Hydrosphere C18 column $(150 \mathrm{~mm} \times 3.0 \mathrm{~mm}$ i.d., YMC, Kyoto, Japan), and a UV-Vis detector (SPD-10AV VP, Shimadzu, Kyoto, Japan). The sample was isocratically eluted with distilled water for the first $10 \mathrm{~min}$, and the concentration of acetonitrile was thereafter linearly increased up to $100 \%$ at $2 \% / \mathrm{min}$. Pure acetonitrile was pumped for the final 20 min. The flow rate of the mobile phase was $0.4 \mathrm{~mL} / \mathrm{min}$. The absorbances at $220 \mathrm{~nm}$ and $280 \mathrm{~nm}$ were both recorded.

\subsubsection{Antioxidative ability in rancidity test}

Based on the principle of the Rancimat method ${ }^{23)}$, the evaluation system for the antioxidative ability in the rancidity test was fabricated by ourselves ${ }^{22}$. In short, a linoleic acid-methanol solution (containing $100 \mathrm{mg}$ linoleic acid) was mixed with $1 \mathrm{mg}$ of the extract in a glass tube and then all the solvents were removed from the solution under reduced pressure. The sample tube was subsequently capped with a silicone stopper with two inserted pipes. Fresh air was pumped at $10 \mathrm{~L} / \mathrm{h}$ through one pipe to the sample by an air pump (AP-032ZN, Iwaki, Tokyo, Japan), while the sample tube was heated at $105^{\circ} \mathrm{C}$ by a heater (Dry thermo unit DTU-1B, Taitech, Saitama, Japan). Air flown out through the other pipe was bubbled into distilled water $(50 \mathrm{~mL})$ to trap any volatile oxidation products. The conductance of the water was recorded every five minutes by an LCR-meter (AD-5827, A\&D, Tokyo, Japan). Linoleic acid without the extract was used as the control. The induction period for the oxidation of linoleic acid was estimated by the time for the abrupt increase in the conductance.

2.3.8 Antioxidative ability in bulk oil system

The antioxidative ability of the extract in the bulk oil system was evaluated by measuring the fraction of unoxidized linoleic acid by gas chromatography (GC) with some modifications ${ }^{24,31)}$. Solutions of linoleic acid and the extract were prepared at $2.24 \%(\mathrm{w} / \mathrm{w})$ by dissolving them in methanol to prepare the linoleic acid with $1 \%(\mathrm{w} / \mathrm{w})$ of the extract. A sample $(0.3 \mathrm{~mL})$ was placed in a glass cup $(30$ $\mathrm{mm} \times 15 \mathrm{~mm}$ i.d.), and the methanol was removed under reduced pressure. The cup containing the sample was then put into a desiccator where phosphorus pentoxide was placed to keep the relative humidity around $0 \%$. The desiccator with the samples was placed in an oven (DNF-400, Yamato Scientific, Tokyo, Japan) at $60^{\circ} \mathrm{C}$. At appropriate intervals (30 min to $3 \mathrm{~h}$ ), a cup was removed from the desiccator and the sample was re-dissolved in methanol $(0.3$ $\mathrm{mL})$. One percent $(\mathrm{w} / \mathrm{w})$ of methyl palmitate dissolved in methanol $(300 \mu \mathrm{L})$ was well mixed with the sample before the GC analysis. A GC-2014 gas chromatograph (Shimadzu, Kyoto, Japan) equipped with a DB-1 capillary column (30 m $\times 0.25 \mathrm{~mm}$ i.d., J\&W Scientific, Folsom, CA, USA) was used. Helium gas was used as the carrier gas, and the temperatures of the injector, column, and FID detector were set at $280^{\circ} \mathrm{C}, 260^{\circ} \mathrm{C}$, and $300^{\circ} \mathrm{C}$, respectively. Methyl palmitate was used as the internal standard during the GC analysis. The fraction of the unoxidized linoleic acid was calculated by dividing the peak area of the linoleic acid with that of methyl palmitate.

\section{RESULTS AND DISCUSSION}

\subsection{Extraction from defatted rice bran}

The defatted rice bran was treated with various extractants at $230^{\circ} \mathrm{C}$ for $5 \mathrm{~min}$. As shown in Table 1, treatment with $50 \%(\mathrm{v} / \mathrm{v})$ acetone produced the highest yield of 0.549 g/g-bran. The treatments with ethanol and acetone gave lower yields than those with water, $50 \%(\mathrm{v} / \mathrm{v})$ ethanol, and $50 \%(\mathrm{v} / \mathrm{v})$ acetone. This fact indicates that water played an important role during the treatments. Since water has the ability to hydrolyze substances via an acid- or base-catalyzed pathway ${ }^{32}$ due to its high ion product, the water would facilitate the liberation of compounds bound to the carbohydrate backbone of the bran.

Concerning the composition of the extracts, as shown in Table 1, the extracts with $50 \%(\mathrm{v} / \mathrm{v})$ acetone and $50 \%(\mathrm{v} / \mathrm{v})$ ethanol showed the highest DPPH radical scavenging activity and total carbohydrate content, respectively. The extract with acetone possessed the highest protein and total phenolic contents. Among all the extracts, the extract with water showed the lowest levels of all the measurements except for the yield. The extract with $50 \%(\mathrm{v} / \mathrm{v})$ acetone possessed a 4 times higher DPPH radical scavenging activity than that using water.

\subsection{UV spectra and HPLC analyses of the defatted rice bran extracts}

The concentrations of the extract solutions obtained by the treatments with water, $50 \%(\mathrm{v} / \mathrm{v})$ ethanol, ethanol, $50 \%$ $(\mathrm{v} / \mathrm{v})$ acetone, and acetone were 8.62, 10.12, 5.34, 10.98, and $3.08 \mathrm{mg} / \mathrm{mL}$, respectively. As shown in Fig. 1, the spectrum of the extract with $50 \%(\mathrm{v} / \mathrm{v})$ acetone showed generally higher absorbance than the others due to its high con- 


\section{T.-Y. Chiou, A. Ogino, T. Kobayashi et al.}

Table 1 Properties of the extracts obtained using various extractants at $230^{\circ} \mathrm{C}$ for $5 \mathrm{~min}$.

\begin{tabular}{cccccc}
\hline Extractant & Water & $50 \%$ Ethanol & Ethanol & $50 \%$ Acetone & Acetone \\
\hline $\begin{array}{c}\text { Yield [g/g-bran] } \\
\text { Total carbohydrate content } \\
\text { [g/g-extract] }\end{array}$ & 0.431 & 0.506 & 0.267 & 0.549 & 0.154 \\
$\begin{array}{c}\text { Protein content } \\
\text { [g/g-extract] }\end{array}$ & $0.330 \pm 0.010$ & $0.587 \pm 0.014$ & $0.591 \pm 0.023$ & $0.791 \pm 0.019$ & $0.896 \pm 0.006$ \\
$\begin{array}{c}\text { Total phenolic content } \\
\text { [g/g-extract] }\end{array}$ & $0.072 \pm 0.001$ & $0.098 \pm 0.001$ & $0.084 \pm 0.007$ & $0.107 \pm 0.004$ & $0.169 \pm 0.006$ \\
$\begin{array}{c}\text { DPPH radical scavenging } \\
\text { activity [mmol-VC/g-extract] }\end{array}$ & $0.123 \pm 0.006$ & $0.330 \pm 0.076$ & $0.217 \pm 0.048$ & $0.495 \pm 0.016$ & $0.403 \pm 0.032$ \\
\hline
\end{tabular}

Except for the yield $(n=1)$, all the measurements were carried out in triplicate and presented as mean \pm standard deviation.

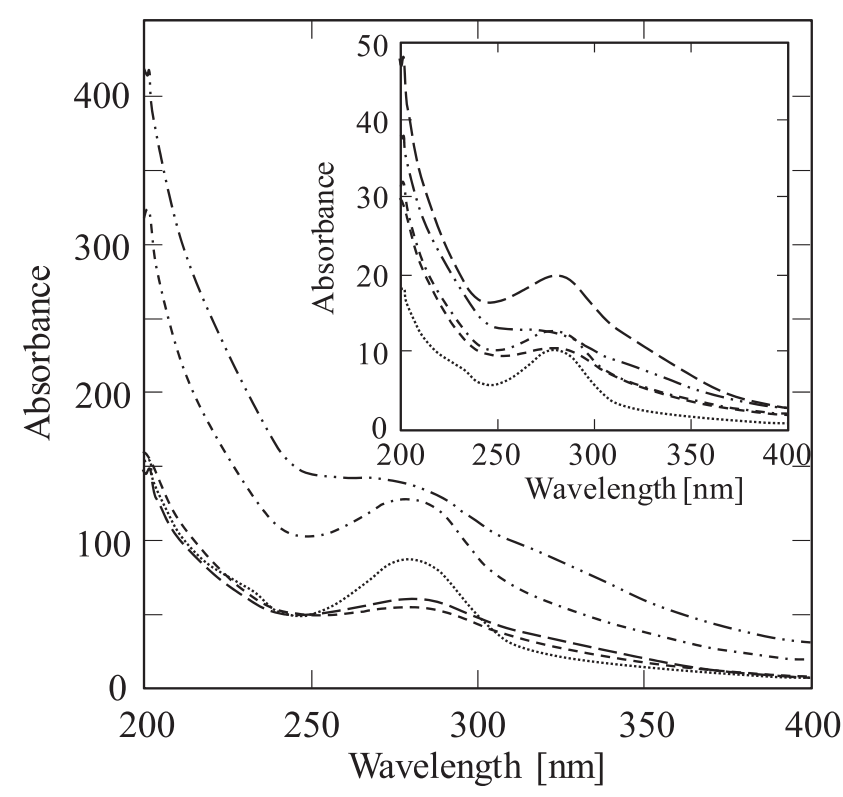

Fig. 1 UV spectra of defatted rice bran extracts obtained with water $(\cdots), 50 \%(\mathrm{v} / \mathrm{v})$ acetone $(-$ $\cdots)$, acetone $(--), 50 \%(\mathrm{v} / \mathrm{v})$ ethanol $(-\cdot-)$, and ethanol (- - ) at $230^{\circ} \mathrm{C}$ for $5 \mathrm{~min}$. The inset shows spectra of the extracts with the concentrations converted to $1 \mathrm{mg} / \mathrm{mL}$.

centration. The inset of Fig. 1 illustrates the absorption spectra at the concentration converted to $1 \mathrm{mg} / \mathrm{mL}$, and the extract with acetone showed the highest absorbance, especially around $280 \mathrm{~nm}$. Moreover, the absorbances around $280 \mathrm{~nm}$ of the $50 \%(\mathrm{v} / \mathrm{v})$ ethanol and $50 \%(\mathrm{v} / \mathrm{v})$ acetone extracts were higher than those of ethanol and water extracts. The tendency was similar to the order in the total phenolic content of the extracts (Table 1).

The HPLC analyses of the extracts were also carried out. The elution profiles were monitored at 220 and $280 \mathrm{~nm}$, at which acyclic dienes ${ }^{33)}$ and aromatics have strong absorbances, respectively. As shown in Fig. 2 (a), hydrophilic
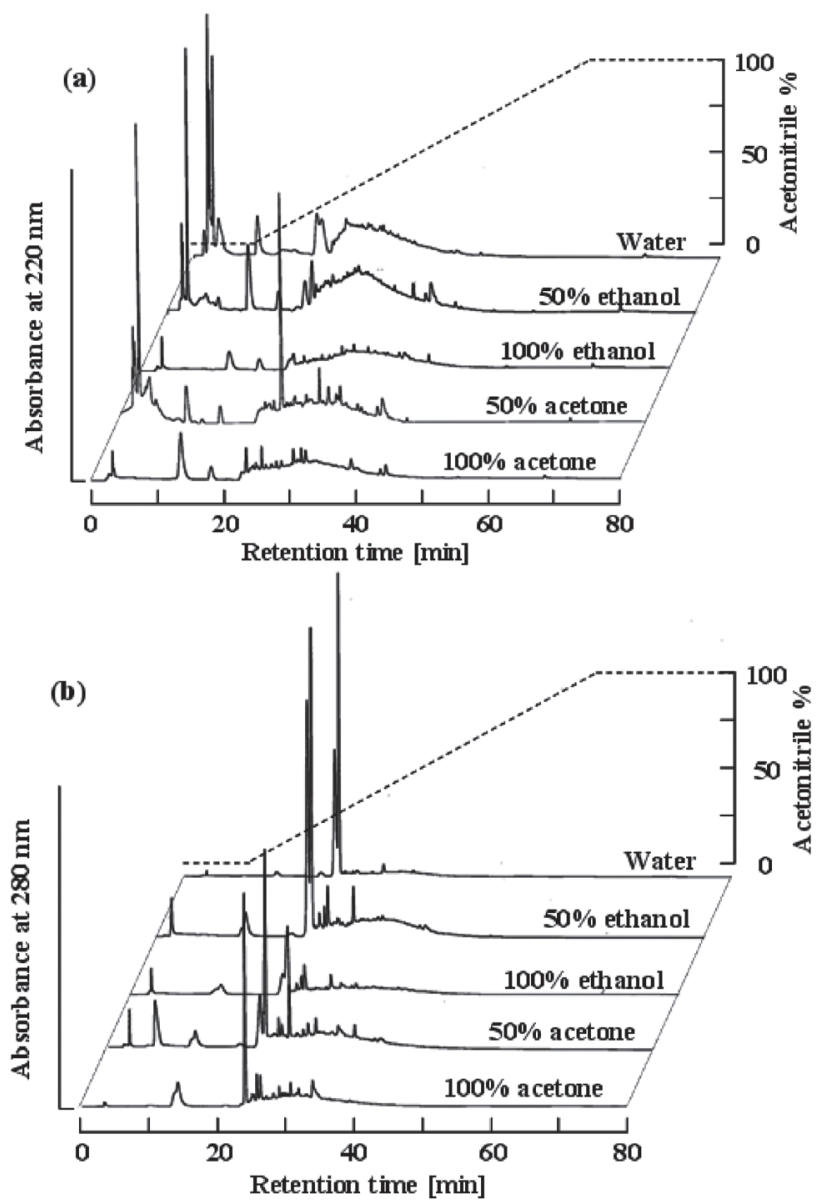

Fig. 2 HPLC chromatograms of defatted rice bran extracts obtained with various extractants at $230^{\circ} \mathrm{C}$ for $5 \mathrm{~min}$. The elution profiles were monitored at (a) $220 \mathrm{~nm}$ and (b) $280 \mathrm{~nm}$.

substances with an absorbance at $220 \mathrm{~nm}$ were eluted within the first $10 \mathrm{~min}$, especially for the extracts with water, $50 \%(\mathrm{v} / \mathrm{v})$ ethanol, and $50 \%(\mathrm{v} / \mathrm{v})$ acetone. On the other hand, peaks with a high absorbance at $280 \mathrm{~nm}$ were 


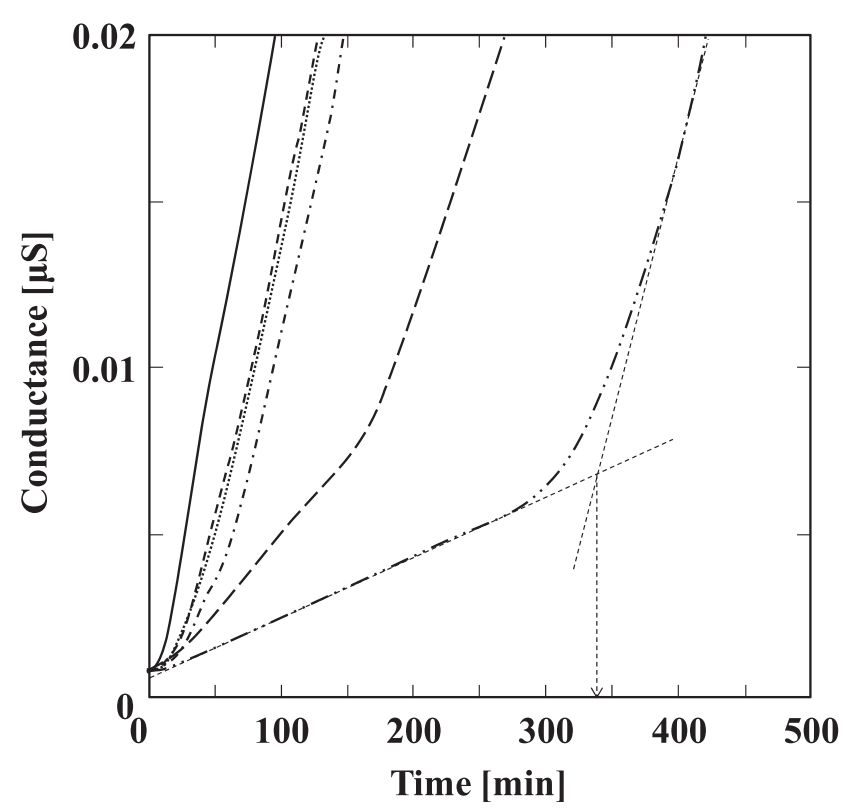

Fig. 3 Time course of conductance in the rancidity test for the extracts obtained with water $(\cdots), 50 \%$ $(\mathrm{v} / \mathrm{v})$ ethanol $(-\cdot-)$, ethanol $(---), 50 \%(\mathrm{v} / \mathrm{v})$ acetone $(-\cdots)$, and acetone $(--)$ at $230^{\circ} \mathrm{C}$ for 5 min. The control (-) was carried out without any extract. The arrow indicates the estimation of induction for the extract with $50 \%(\mathrm{v} / \mathrm{v})$ acetone.

observed near $25 \mathrm{~min}$, while only a few peaks were observed in the first 10 min as shown in Fig. 2(b). The peaks that appeared around 20-40 min would be ascribed to relatively hydrophobic substances, and the extracts with $50 \%$ $(\mathrm{v} / \mathrm{v})$ ethanol and $50 \%(\mathrm{v} / \mathrm{v})$ acetone possessed these substances more than the extracts with ethanol, acetone, and water. The hydrophobic substances seemed to correspond to phenolic compounds due to their high absorbance at 280 nm.

\subsection{Antioxidative ability of the defatted rice bran extracts} 3.3.1 Rancidity test

Figure 3 shows the time course of conductance during the rancidity test for the various extracts. Estimation of the induction period is indicated by the thin broken lines for the linoleic acid containing the extract with $50 \%(\mathrm{v} / \mathrm{v})$ acetone. The rancidity test for the extract with $50 \%(\mathrm{v} / \mathrm{v})$ acetone showed the longest induction period among all the extracts (Table 2), indicating that the extract with $50 \%$ (v/ v) acetone had the strongest antioxidative ability against the oxidation of linoleic acid. The extract with acetone showed the second-strongest antioxidative ability. The extract with ethanol, $50 \%(\mathrm{v} / \mathrm{v})$ ethanol, and water showed a slightly longer induction period than the control. The order of induction period in the rancidity test corresponded to that of the DPPH radical scavenging activity (Table 1 and Table 2). In the rancidity test, the induction periods of the linoleic acid containing the extracts with water and $50 \%$ acetone were lengthened by around 2 and 15 times, respectively, compared to that of the linoleic acid without any extract. The relatively larger deviation was observed for the induction period in the presence of the extract with $50 \%(\mathrm{v} / \mathrm{v})$ acetone. Antioxidant ability was reported to be affected by its affinity toward the air-oil interface ${ }^{34)}$. The extract seemed to be located at the air-oil interface. The non-uniform distribution of the extract would be the reason for the deviation.

Although an induction period could be estimated by the rancidity test, the oxidation rate constant for linoleic acid could not be determined. In order to investigate the effect of the extracts on the oxidation rate constant, the oxidation of linoleic acid treated with extracts was then carried out in the bulk oil system.

Table 2 Antioxidative ability of the extracts in the rancidity test and bulk oil system.

\begin{tabular}{cccc}
\hline \multirow{2}{*}{ Extractant } & Rancidity test $^{* 1}$ & \multicolumn{2}{c}{ Bulk oil system $^{* 2}$} \\
\cline { 2 - 4 } & Induction period $[\mathrm{h}]$ & $k\left[\mathrm{~h}^{-1}\right]$ & Induction period $[\mathrm{h}]$ \\
\hline Control & $0.32 \pm 0.02$ & 0.56 & 3.12 \\
Water & $0.58 \pm 0.09$ & 0.36 & 7.54 \\
$50 \%$ ethanol & $0.78 \pm 0.09$ & 0.34 & 12.5 \\
Ethanol & $0.55 \pm 0.14$ & 0.39 & 10.9 \\
$50 \%$ acetone & $4.90 \pm 0.99$ & 0.37 & 14.4 \\
Acetone & $2.68 \pm 0.02$ & 0.44 & 13.2 \\
\hline
\end{tabular}

${ }^{* 1}$ Oxidation of linoleic acid in the rancidity test was carried out in triplicate at $105^{\circ} \mathrm{C}$ with flowing fresh air.

${ }^{*}$ Oxidation of linoleic acid in the bulk system was carried out singly at $60^{\circ} \mathrm{C}$ in a sealed bottle. 


\section{T.-Y. Chiou, A. Ogino, T. Kobayashi et al.}

\subsubsection{Bulk oil system}

According to our previous report ${ }^{24)}$, the oxidation of linoleic acid can be expressed as follows:

$$
\frac{d Y}{d t}=k Y(1-Y)
$$

where $Y$ is the fraction of unoxidized linoleic acid, and $k$ is the oxidation rate constant of linoleic acid. Equation(3) can be obtained by integrating Eq. (2) under the initial condition of $Y=Y_{0}$ at $t=0$.

$$
Y=\frac{1}{1+\exp \left(k t+\ln \frac{1-Y_{0}}{Y_{0}}\right)}
$$

The rate constants, $k$ and $Y_{0}$, by which the calculated results were best-fitted to the experimental ones, were estimated as follows: a tentative $k$ was estimated by dividing the value of $-\ln \left[\left(1-Y_{0}\right) / Y_{0}\right]$ at the half-life of the unoxidized fraction $\left(t_{1 / 2}\right)$ under the assumption of $Y_{0}=0.99$. The best $k$ and $Y_{0}$ values were estimated to minimize the residual sum of squares between the observed and predicted $Y$ values using the Solver in Microsoft ${ }^{\circledR}$ Excel 2007. The time courses of the unoxidized fraction are drawn in Fig. 4 based on Eq. (3) using the estimated $k$ and $Y_{0}$. The induction period in this system was estimated from the time

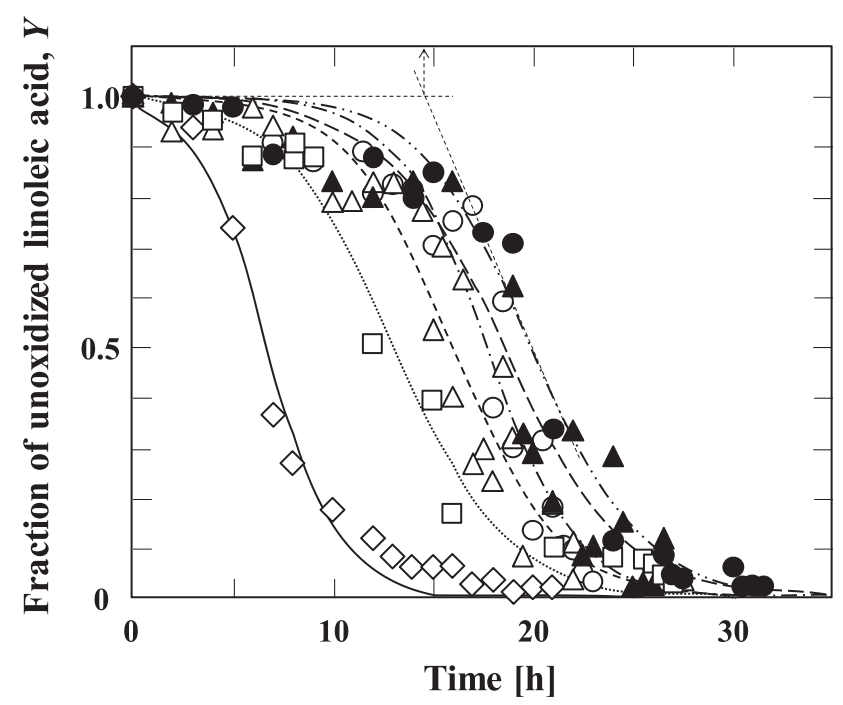

Fig. 4 Changes in the fraction of unoxidized linoleic acid in the bulk oil system. The extracts obtained with water $(\square, \cdots), 50 \%(\mathrm{v} / \mathrm{v})$ ethanol $(\boldsymbol{\Delta},-$ $\cdot-)$, ethanol ( $\triangle$, - - - ), 50\% (v/v) acetone $(\mathbf{O}$, $-\cdots)$, and acetone $(\mathrm{O},--)$ at $230^{\circ} \mathrm{C}$ for $5 \mathrm{~min}$ were separately added to the linoleic acid at the concentration of $1 \%(\mathrm{w} / \mathrm{w})$. Control $(\diamond,-)$ was carried out without any extract. The curves were calculated using the best-fitted $k$ and $Y_{0}$ values. The arrow indicates induction period for the linoleic acid added by the extract with $50 \%(\mathrm{v} / \mathrm{v})$ acetone. where the tangential line of the curve at $t_{1 / 2}$ intersected with $Y=1$ as shown by the thin broken lines.

In the bulk oil system at $60^{\circ} \mathrm{C}$, all the extracts elongated the induction period of the linoleic acid (Table 2). The induction periods for the extracts with water and $50 \%$ acetone were lengthened by 2.4 and 4.6 times, respectively. On the other hand, the rate constants, $k$, for the linoleic acid with these extracts were only slightly lower than that for the linoleic acid without any extract. The results of rancidity tests and test in bulk oil system show that the extracts obtained by the treatment with a subcritical fluid, especially $50 \%(\mathrm{v} / \mathrm{v})$ acetone, scarcely affect the oxidation rate constant of linoleic acid but greatly prolong the induction period. That is, the extracts seem to be able to scavenge the radicals generated during the initiation step of the oxidation of linoleic acid but to be hard to suppress the progress of the propagation step.

\section{CONCLUSION}

In the treatments of defatted rice bran with the subcritical fluids, the $50 \%(\mathrm{v} / \mathrm{v})$ acetone showed the high extraction efficiency for the protein and total phenolic contents. The extracts with $50 \%(\mathrm{v} / \mathrm{v})$ acetone also possessed the highest $\mathrm{DPPH}$ radical scavenging activity which was 4 times higher than that of the extract with water. HPLC analyses and the UV spectra indicated that the extract with $50 \%(\mathrm{v} / \mathrm{v})$ acetone contained more hydrophobic substances, which seemed to be aromatic compounds. The extract with 50\% $(\mathrm{v} / \mathrm{v})$ acetone showed the longest induction periods in both the rancidity test and bulk oil system, suggesting that the extract possessed the highest antioxidative ability among all the extracts. The extracts obtained using the various solvents had no effect on the oxidation rate of linoleic acid in the bulk system since there was no obvious difference among the $k$ values.

\section{ACKNOWLEDGEMENT}

One of the authors (T.-Y. C.) would like to thank the Interchange Association, Japan(IAJ), for the scholarship support.

\section{References}

1) Saunders, R. M. Rice bran: Composition and potential food uses. Food Rev. Intl. 1, 465-495 (1985-1986).

2) Helm, R. M.; Burks, A. W. Hypoallergenicity of rice protein. Cereal Foods World 41, 839-843(1996).

3) Qureshi, A. A.; Sami, S. A.; Khan, F. A. Effects of stabilized rice bran, its soluble and fiber fractions on blood 
glucose levels and serum lipid parameters in humans with diabetes mellitus Types I and II. J. Nutr. Biochem. 13, 175-187 (2002).

4) Zhou, Z.; Robards, K.; Helliwell, S.; Blanchard, C. The distribution of phenolic acids in rice. Food Chem. 87, 401-406 (2004).

5) Pourali, O.; Asghari, F. S.; Yoshida, H. Production of phenolic compounds from rice bran biomass under subcritical water conditions. Chem. Eng. J. 160, 259266 (2010).

6) Caasi-Lit, M.; Whitecross, M. I.; Nayudu, M.; Tanner, G. J. UV-B Irradiation induces differential leaf damage, ultrastructural changes and accumulation of specific phenolic compounds in rice cultivars. Aust. J. Plant Physiol. 24, 261-274(1997).

7) Zhao, Z.; Moghadasian, M. H. Chemistry, natural sources, dietary intake and pharmacokinetic properties of ferulic acid: A review. Food Chem. 109, 691-702 (2008).

8) Chen, C. H.; Yang, Y. H.; Shen, C. T.; Lai, S. M.; Chang, C. M. J.; Shieh, C. J. Recovery of vitamins B from supercritical carbon dioxide-defatted rice bran powder using ultrasound water extraction. J. Taiwan Inst. Chem. Engrs. 42, 124-128(2011).

9) Saad, N.; Esa, N. M., Ithnin, H.; Shafie, N. H. Optimization of optimum condition for phytic acid extraction from rice bran. African J. Plant Sci. 5, 168-176 (2011).

10) Patindol, J.; Wang, L.; Wang, Y. J. Cellulase-assisted extraction of oligosaccharides from defatted rice bran. J. Food Sci. 72, 516-521(2007).

11) Abdul-Hamid, A.; Luan, Y. S. Functional properties of dietary fibre prepared from defatted rice bran. Food Chem. 68, 15-19 (2000).

12) Aoe, S.; Oda, T.; Tatsumi, K.; Yamauchi, M.; Ayano, Y. Extraction of soluble dietary fibers from defatted rice bran. Cereal Chem. 70, 423-425 (1993).

13) Tang, S.; Hettiarachchy, N. S.; Shellhammer T. H. Protein extraction from heat-stabilized defatted rice bran. 1. Physical processing and enzyme treatments. J. $A g$ ric. Food Chem. 50, 7444-7448(2002).

14) Chittapalo, T.; Noomhorm, A. Ultrasonic assisted alkali extraction of protein from defatted rice bran and properties of the protein concentrates. Int. J. Food Sci. Technol. 44, 1843-1849(2009).

15) Sereewatthanawut, I.; Prapintip, S.; Watchiraruji, K., Goto, M.; Sasaki, M.; Shotipruk, A. Extraction of protein and amino acids from deoiled rice bran by subcritical water hydrolysis. Bioresour. Technol. 99, 555561 (2008).

16) González-Rodríguez, J.; Pérez-Juan, P.; Luque de Castro, M. D. Extraction of wood compounds by use of subcritical fluids. Chromatographia 57, 363-368 (2003).
17) Hasegawa, I.; Tabata, K.; Okuma, O.; Mae, K. New pretreatment methods combining a hot water treatment and water/acetone extraction for thermo-chemical conversion of biomass. Energy \& Fuels 18, 755-760 (2004).

18) Field, J. A.; Reed, R. L. Subcritical(hot)water/ethanol extraction of nonylphenol polyethoxy carboxylates from industrial and municipal sludges. Environ. Sci. Technol. 33, 2782-2787 (1999).

19) Jiménez, L.; García, J. C.; Pérez, I.; Ferrer, J. L.; Chica, A. Influence of the operating conditions in the acetone pulping of wheat straw on the properties of the resulting paper sheets. Bioresour. Technol. 79, 23-7(2001).

20) Chiou, T.-Y.; Neoh T. L.; Kobayashi, T.; Adachi, S. Properties of extract obtained from defatted rice bran by extraction with aqueous ethanol under subcritical conditions. Food Sci. Technol. Res. 18, 37-45 (2012).

21) Chiou, T.-Y.; Neoh T. L.; Kobayashi, T.; Adachi, S. Extraction of defatted rice bran with subcritical aqueous acetone. Biosci. Biotechnol. Biochem. (in press).

22) Chiou, T.-Y.; Neoh, T. L.; Kobayashi, T.; Adachi, S. Antioxidative ability of defatted rice bran extract obtained by subcritical water extraction in bulk oil and aqueous dispersion systems. Jpn. J. Food Eng. 12, 147-154 (2011).

23) Läubli, M. W.; Bruttel, P. A. Determination of the oxidative stability of fats and oils: Comparison between the active oxygen method (AOCS Cd 12-57) and the Rancimat method. J. Am. Oil Chem. Soc. 63, 792-795 (1986).

24) Adachi S.; Ishiguro T.; Matsuno R. Autoxidation kinetics for fatty acids and their esters. J. Am. Oil Chem. Soc. 72, 547-551 (1995).

25) AOCS Official methods and recommended practices of the AOCS, 5th ed. American Oil Chemists' Society, Champaign, IL (1998).

26) Dubois, M.; Gilles, K. A.; Hamilton, J. K., Rebers, P. A.; Smith, F. Colorimetric method for determination of sugars and related substances. Anal. Chem. 28, 350356 (1956).

27) Lowry, O. H.; Rosebrough, N. J.; Farr, A. L.; Randall, R. J. Protein measurement with the Folin phenol reagent. J. Biol. Chem. 193, 265-275(1951).

28) Singleton, V. L.; Rossi, J. A. Jr. Colorimetry of total phenolics with phosphomolybdic-phosphotungstic acid reagents. Am. J. Enol. Vitic. 16, 144-158(1965).

29) Wiboonsirikul, J.; Khuwijitjaru, P.; Kimura, Y.; Morita, H.; Tsuno, T.; Adachi, S. Production optimization of the extract with high phenolic content and radical scavenging activity from defatted rice bran by subcritical water treatment. Jpn. J. Food Eng. 8, 311-315 (2007).

30) Fujinami, Y.; Tai, A.; Yamamoto, I. Radical scavenging activity against 1,1-diphenyl-2-picrylhydrazyl of ascor- 
bic acid 2-glucoside (AA-2G) and 6-acyl-AA-2G. Chem. Pharm. Bull. 49, 642-644(2001).

31) Wiboonsirikul, J.; Kimura, Y.; Kadota, M.; Morita, H.; Tsuno, T.; Adachi, S. Properties of extracts from defatted rice bran by its subcritical water treatment. $J$. $A g$ ric. Food Chem. 55, 8759-8765 (2007).

32) Patrick, H. R.; Griffith, K.; Liotta, C. L.; Eckert, C. A.; Gläser, R. Near-critical water: A benign medium for catalytic reactions. Ind. Eng. Chem. Res. 40, 6063-
$6067(2001)$.

33) Carey, F. A.; Sundberg, R. J. Advanced Organic Chemistry Part A: Structure and Mechanisms. 5th ed. Springer Science+Business Media, New York, USA. p. 1074.

34） Frankel, E. N.; Huang, S.-W.; Kanner, J.; German J. B. Interfacial phenomena in the evaluation of antioxidants: bulk oils vs emulsions. J. Agri. Food Chem. 42, 1054-1059 (1994). 